\section{Synthesis of the First FDA-Approved HIV Protease Inhibitor}

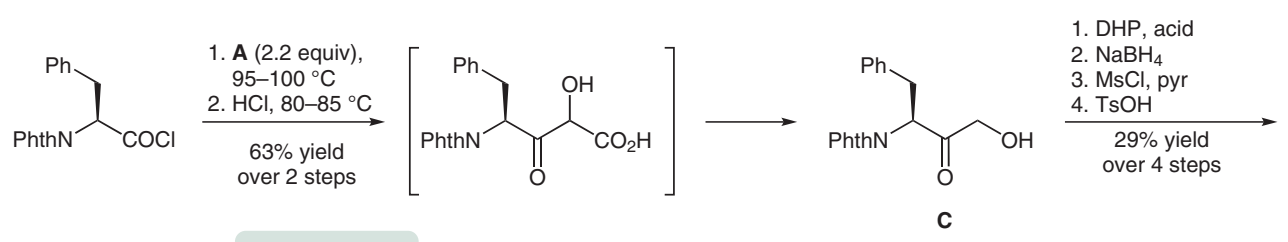

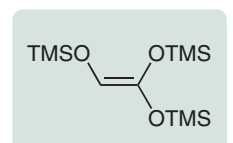

A

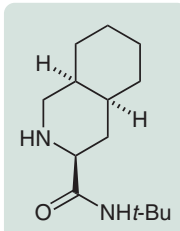

B<smiles>CCCNC(=O)[C@@H]1C[C@H]2CCCC[C@H]2CN1C[C@H](O)[C@@H](Cc1ccccc1)Nc1ccccc1</smiles><smiles>CO[C@H](CO)C(Cc1ccccc1)Nc1ccccc1</smiles><smiles>c1ccc(CC(Nc2ccccc2)C2CO2)cc1</smiles>

Category

Chemistry in

Medicine and Biology

\section{Key words}

\section{HIV protease}

antiretroviral

saquinavir

ritonavir
Significance: Human immunodeficiency virus (HIV) encodes for a protease that processes polyproteins into structural proteins and essential viral enzymes. The HIV protease became a focus of intensive, international drug discovery efforts, leading to the discovery of saquinavir (Ro 31-8959), which became the first FDA-approved HIV protease inhibitor in 1995. It can be used in combination with ritonavir, another protease inhibitor, as part of an FDA-approved, boosted protease inhibitor regimen whereby a low dose of ritonavir is used to inhibit cytochrome P450 3A4 (CYP3A4), reducing the metabolism of saquinavir and increasing its bioavailability.
Comment: Starting from $\mathrm{N}$-phthaloyl-L-phenylalaninyl chloride, homophenylalanine $\mathbf{C}$ is prepared according to chemistry developed by Wissner (J. Org. Chem. 1979, 44, 4617). Reduction of hydroxyketone C affords the Felkin product, which is cyclized to key intermediate $\mathbf{D}$. Decahydroisoquinoline $\mathbf{B}$ opens the protected epoxide and the sequence is elaborated with two peptide couplings to yield saquinavir. This route was used to prepare kilogram quantities of the drug (Kevin E. B. Parkes et al. J. Org. Chem.1994, 59, 3656). 